\title{
MEASURING THE PREDICTIVE VALUE OF SEROLOGICAL QUANTIFICATION OF CYTOKINES WITH THE ONSET OF INFLUENZA-LIKE SIGNS AND SYMPTOMS INDUCED BY IMIQUIMOD 3.75\% CREAME RESULTS OF A SINGLE GENTER, OPEN-LABEL, PROOF OF CONGEPT TRIAL
}

Neal Bhatia, M.D.

Therapeutics Clinical Research, San Diego, CA

\section{INTRODUCTION}

Imiquimod is an immune response modifier that is FDA approved for the treatment of actinic keratosis (AKs), external genital warts, an superficial basal cell carcinoma.

Imiquimod is a potent inducer of interferon (IFN)- $\alpha$ and other pro-inflammatory cytokines.

Some patients treated with topical imiquimod develop influenza-like symptoms (e.g., myalgia, malaise, headache, low-grade fever, and fatigue) that may be related to elevated levels of pro-inflammatory cytokines associated with application of the drug

This study was carried out to assess correlations between influenza-like symptoms and cytokine levels in patients who applied imiquimod cream to their skin for 14 days. Other variables that might influof local skin reactions, the amount of surface area involved, and the area of the body exposed were also evaluated.

METHODS

Design

Single-center open-label study.

Subjects

22 men and women with 5-20 AKs between 30 and 89 years of age.

Treatment

The designated treatment area (entire face or balding scalp; or ches or upper extremities) was cleansed with an approved cleanser and allowed to dry for 5 minutes prior to application of imiquimod $3.75 \%$ cream to a total are of $200 \mathrm{~cm}^{2}$. The treatment period was 14 days.

Endpoints

Clearance of AKs

Frequency of symptoms indicative of an influenza-like response, in cluding, fever, headache, fatigue, malaise, gastrointestinal symptoms, dizziness, myalgia, and arthralgia.

Change from baseline at subsequent study visits (days $8,15,43$, and 57 [end of study]) in:

Cytokines - interleukin (IL) -6, IL-8, IL-12, IL-13, IL-2 receptor (R) tumor necrosis factor- $\alpha$ (TNF), IFN- $\alpha$, and IFN- $\gamma$

Frequency of local skin reactions of erythema, scabbing/crusting edema, erosion/ulceration, exudate, flaking/scaling/dryness and

RESULTS

Subjects

Characteristics of subjects enrolled and areas treated are summarized in Table 1.

Clearance of AKs

All but one subject experienced either complete clearance or partial clearance of actinic keratoses with no more than 3 remaining in the treatment field

Table 1. Subject characteristics

\section{Characteristic}

Age (years)

Mean (standard deviation)

Median

Age group, $\mathrm{n}(\%)$

$\geq 30$ years to $\leq 59$ years

$\geq 60$ years to $\leq 89$ years

Sex, $n(\%)$

Female

Male

Area of Treatment $n(\%)$

Entire Face or Balding Scalp

Chest or Upper Extremities
Frequency of Influenza-like Symptoms

Systemic symptoms characteristic of influenza occurred infrequently during the treatment period (Table 2).

Table 2. Influenza-like symptoms that emerged during treatment

\begin{tabular}{|l|c|}
\multicolumn{1}{c|}{ Symptom } & \multicolumn{1}{c|}{$\begin{array}{c}\text { Occurrence } \\
\text { During Treatment } \\
\text { (n) }\end{array}$} \\
\hline Fever & 1 \\
\hline Myalgia & 1 \\
\hline Fatigue & 0 \\
\hline Malaise & 1 \\
\hline Headache & 4 \\
\hline Gastrointestinal symptoms & 3 \\
\hline Dizziness & 3 \\
\hline Arthralgia & 3 \\
\hline
\end{tabular}

Relationship Between Clearance of AKs and Influenza-like Symptoms

There was no apparent relations
rence of symptoms (Table 3 )

Table 3. AK clearance in subjects with and without influenza-like symptoms

\begin{tabular}{|c|c|c|}
$\begin{array}{c}\text { Systemic Symptoms } \\
\text { during treatment }\end{array}$ & $\begin{array}{c}\text { Baseline AK count, } \\
\text { mean (median) }\end{array}$ & $\begin{array}{c}\text { End of treatment } \\
\text { AK count, } \\
\text { mean (median) }\end{array}$ \\
\hline Yes & $14.0(14.0)$ & $2.9(0.0)$ \\
\hline No & $13.7(14.0)$ & $2.4(1.0)$ \\
\hline
\end{tabular}

Changes from Baseline in Cytokine Levels

Twelve subjects had elevations in at least one cytokine at one or more post-baseline visits (Table 4)

There were no apparent relationships between the occurrences of cytokine elevations and either the occurrence of influenza-like symptoms or local skin reactions (Figure 1).

Table 4. Cytokine elevations during treatment.

\begin{tabular}{|c|c|c|c|c|}
\hline Subject & Visit 1 & Visit 2 & Visit 3 & Visit 4 \\
\hline 4 & IL-2 & IL-2 & IL-2, IL-13 & $\begin{array}{l}\text { IL-2, IL-2R, } \\
\text { IL-13 }\end{array}$ \\
\hline 7 & & & IL-13 & IL-13 \\
\hline 8 & IFN- $\gamma$ & IFN- $\gamma$ & IFN- $\gamma$ & IFN- $\gamma$ \\
\hline 10 & & IL-2, IL-12 & IL-2 & $\begin{array}{l}\text { IL-2, IL-12, } \\
\text { IFN- } \gamma\end{array}$ \\
\hline 11 & $\begin{array}{c}\text { IL-6, IL-2R, } \\
\text { IL-13 }\end{array}$ & $\begin{array}{l}\text { IL-6, IL-2R, } \\
\text { IL-13 }\end{array}$ & $\begin{array}{c}\text { IL-6, IL-2R, } \\
\text { IL-13 }\end{array}$ & \\
\hline 12 & & & $\mathrm{IL}-13$ & \\
\hline 13 & IL-13 & & IL-13 & \\
\hline 15 & & & IL-8, IL-13 & \\
\hline 18 & IL-13 & & & \\
\hline 20 & & IL-13 & & IL-13 \\
\hline 21 & IL-13 & IL-12 & & \\
\hline 23 & & IL-8 & IL-13 & IL-13 \\
\hline
\end{tabular}

Figure 1. Temporal relationships among systemic symptoms (SS), local skin reactions (LSR) and elevations in cytokines (EL CYT) for patients with and without SS.

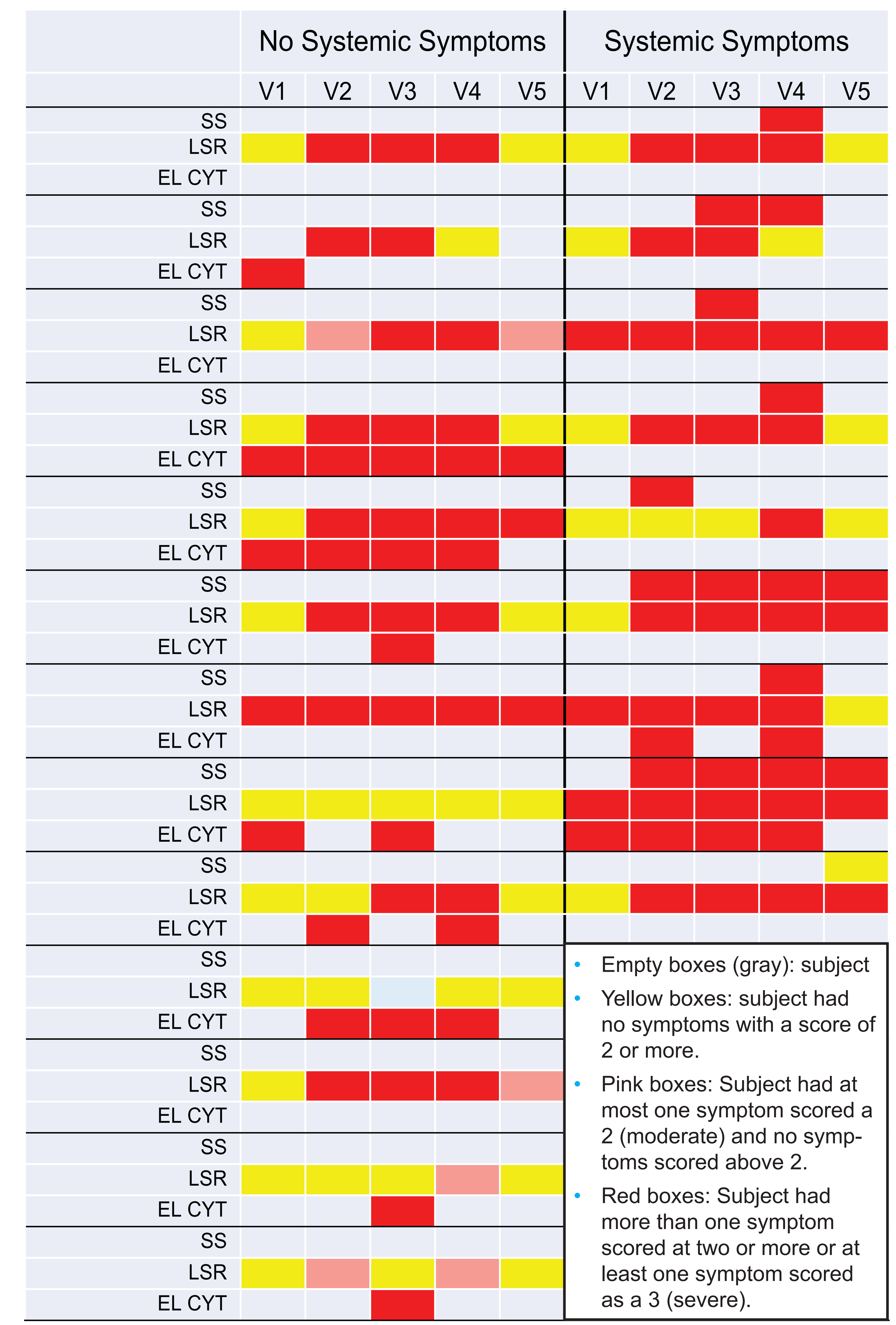

\section{CONCLUSION}

Treatment on the face led to more incidence of flu like symptoms in younger patients

Elevations in pro-inflammatory cytokines did not appear to predict the development of either systemic symptoms or local skin reactions.

Elderly patients treated on the body were less likely to develop reactions of the four groups.

\section{REFERENCES}

1 label/2010/020723s022lbl.pd

2. Nerurkar L, et al. Sci Rep. 2017;7:16570.

3. Cantisani C, et al. Recent Pat Inflamm Allergy Drug Discov. 2012;6:65-69. ACKNOWLEDGMENTS

The author would like to recognize the contributions of AraMed Strategies nc for scientific analysis and editorial support. Study funding was graciously provided by Ortho Dermatologics. 